\title{
La paridad, ¿ un camino a la igualdad? Análisis de las elecciones 2013
}

\section{Gender parity, a path towards equality? An analysis of the 2013 elections}

\section{Solanda Goyes}

Recepción: 25 de junio de 2013

Aceptación: 27 de agosto de 2013

\section{Resumen}

El artículo busca clarificar los alcances del principio y derecho a la paridad, establecida en la Constitución de la República del Ecuador (2008), para luego analizar lo concerniente a la paridad política electoral tomando como base los datos electorales de 2013. Se analiza el cumplimiento de los principales componentes paritarios como el porcentaje de participación de hombres y mujeres en listas de candidaturas pluripersonales y la ubicación dentro de la misma versus los resultados electorales, para determinar el nivel de efectividad del modelo paritario vigente en la incorporación numérica de mujeres a los espacios de elección popular. Finalmente, se indaga en algunos posibles elementos del sistema electoral y de partidos políticos, que podrían influir en la diferencia subsistente entre la participación porcentual de mujeres en las listas de candidaturas con su presencia en el resultado electoral.

Palabras clave: paridad, elecciones, Ecuador, partidos políticos, participación de mujeres.

\begin{abstract}
This article seeks to clarify the scope of the principle and right to "gender parity" established in the Constitution of the Republic of Ecuador in order to then analyze gender parity in politics and elections based on 2013 electoral data. It analyzes the fulfillment of the principle components of gender parity such as the percentage of participation of men and women in electoral lists with multimember elections as well as the placement of names on the list of candidates in relation to the election results. This analysis is used to determine the level of effectiveness of the current gender parity model in the numeric inclusion of women in popular elections. Finally, this article takes a look into several possible elements of the electoral system and political parties which could have an influence on the difference that prevails between the percentage of participation of women in the lists of candidacies and their election results.
\end{abstract}

Keywords: gender parity, elections, Ecuador, political parties, participation of women. 
1 Ecuador es uno de los tres países de América Latina que ha incluido la paridad en su legislación interna, junto a Costa Rica y Bolivia.

La Constitución ecuatoriana de 2008 la consagra en un sentido amplio, como fin y medio para democratizar la sociedad, y plantea un horizonte de transformación de las relaciones entre ciudadanos y ciudadanas; está íntimamente relacionada con el principio de igualdad real y el deber de corresponsabilidad entre hombres y mujeres en las tareas públicas y privadas, elementos que, en conjunto, revelan un esfuerzo por cimentar un nuevo modelo de convivencia cuyos dispositivos apuntan a deconstruir el sistema patriarcal que, por siglos, ha mantenido a las mujeres alejadas del espacio público.

El Artículo 66, numeral 4, de la Carta Fundamental reconoce a las personas el derecho a "... la igualdad formal, igualdad material y no discriminación”. La distinción que la Constitución realiza sobre la igualdad formal y la igualdad material tiene como antecedente el proceso de exigencia de la Ley de Cuotas $(2000)^{1}$, en cuyas acciones de defensa frente a la sistemática violación que de ellas hacían los partidos políticos en el periodo 2000-2007, el Movimiento de Mujeres del Ecuador -que la defendía- tuvo la oportunidad de desarrollar la diferencia entre ambas para justificar la validez de las cuotas a favor de las mujeres ante los tribunales de justicia y ante la opinión pública.

Ese debate, que trascendió y facilitó la constitucionalización de la paridad, también abrió el camino para que la Constitución (2008) consagre la igualdad formal y la igualdad material, principios consustanciales a la democracia y a la paridad.

El Instituto de la Democracia, creado también constitucionalmente, ha considerado importante analizar la paridad a partir de las elecciones de 2013, realizando una generosa invitación para presentar un resumen de esta importante conquista del Movimiento de Mujeres del Ecuador,

1 Se llama Ley de Cuotas al conjunto de artículos de la Ley Orgánica General de Elecciones (derogada) referidos a la participación política de las mujeres en las elecciones. Fue expedida por reforma a la Ley Orgánica General de Elecciones en el año 2000. 
tras una larga lucha por la igualdad que no ha concluido. El Instituto ha proporcionado la información de los datos electorales 2013 y ha realizado el procesamiento de los mismos, para facilitar un análisis de género de dichas elecciones a la luz de los conceptos de paridad e igualdad constantes en la Constitución de la República.

\section{El principio de igualdad formal e igualdad material ${ }^{2}$}

La igualdad formal se encuentra proclamada en casi todas las constituciones del mundo y es el principio por el cual los Estados equiparan a sus ciudadanos y ciudadanas a un mismo sistema jurídico; es la igualdad ante la ley que elimina las anteriores jerarquías sociales y jurídicas (fuente de segregación e injusticia) sometiendo a todos los habitantes de un país a unas mismas reglas y autoridades.

El primer instrumento que la reconoció fue la Declaración de los Derechos del Hombre y del Ciudadano expedida en 1789, resultado de la Revolución Francesa, donde se convierte al principio de igualdad en un enunciado legal, al positivarlo en una norma jurídica que, si bien antes de la misma fue debatido y teorizado por grandes pensadores, no tenía el carácter de obligatorio que adquirió con dicha Declaración.

Con la Revolución se instauró la igualdad ante la ley con el objeto de suprimir un sistema de desigualdades jurídicas en el que se valorizaba la diferencia para otorgar jerarquía a las personas en función de su origen, sexo, religión, etc. La pertenencia a una jerarquía significaba gozar de derechos y privilegios o la exclusión y discriminación, sistema que se encontraba perfectamente reflejado en las normas de la época.

2 Este capítulo es una adaptación del capítulo I de la Tesis Doctoral "El origen jurídico de las desigualdades en la representación electoral de hombres y mujeres en el Ecuador: una propuesta para la igualdad real" (2010), de Solanda Goyes Quelal y del capítulo II, acápite 3.2 del libro La apuesta por la paridad: democratizando el sistema político en América Latina. Los casos de Ecuador, Bolivia y Costa Rica, "De las Cuotas a la Paridad" (2013: 80-83), de la misma autora, publicado por Idea Internacional y por la Comisión Interamericana de Mujeres (CIM) de la Organización de Estados Americanos. 
La igualdad formal llegó para implantar el principio de universalidad de los derechos, declarando que son titulares de los mismos todos los ciudadanos sin distinción alguna. Pero ello trajo consigo la homogenización de las personas y el desconocimiento de las diferencias. Esa homogenización tomó como modelo de ciudadano, titular de derechos, al hombre burgués, blanco, heterosexual, con poder político y económico erigiendo un sistema que favoreció el ejercicio de derechos de quienes seguían ese patrón, y de exclusión para sus diferentes.

Las mujeres, por la diferencia sexual, resultaron excluidas de facto del ejercicio de esos derechos que 'formalmente' aparecían reconocidos para ellas. El derecho al voto para las mujeres fue reconocido, al menos, un siglo después de que se lo reconoció para los varones.

Así, la igualdad formal contempla a los derechos “... en un plano teórico, desconectados de la situación real de la sociedad a la que se dirigen: la igualdad y la libertad son exclusivamente formales, en el convencimiento de que la dinámica de las relaciones sociales, lejos de cualquier intervencionismo estatal, permitirá a cada uno la realización de sus propios derechos" (Valpuesta, 2008: 119). La inefectividad producida por la igualdad formal conduce a su cuestionamiento, especialmente por los movimientos feministas que plantean la necesidad de intervenir para que los derechos de las mujeres se plasmen en la realidad y dejen de ser meras declaraciones.

La igualdad material surge precisamente como un postulado que proclama la igualdad de las personas en tanto sus derechos se ejercen. Contrariamente a la igualdad formal -que plantea la igualdad en la partida-, la igualdad material es una igualdad de resultados, y esta es posible cuando su declaratoria va acompańada de un sistema de garantías que permita efectivizarla, lo que incluye la consideración de la diferencia para equiparar las situaciones de desigualdad. Para Sartori: "iguales tratamientos [leyes iguales] no producen resultados iguales [igualdades en resultados]; de los que se deriva que para convertirse en iguales se necesitan tratamientos desiguales [leyes sectoriales y discriminaciones compensatorias]" (Sartori, 2005: 53). 
Sobre la igualdad material:

...no se define a partir de un criterio de semejanza, sino de justicia: se otorga el mismo valor a personas diversas, integrantes de una sociedad. La igualdad es importante justamente entre diferentes, ya que se trata de una convención social, de un pacto, según el cual se reconoce como iguales a quienes pertenecen a distintos sexos, razas, etnias, clases sociales, etc. El principio de igualdad está estrechamente relacionado con el ejercicio de la tolerancia: el reconocimiento del otro o de la otra como igual, es decir, que siendo distinto o distinta a mí, tiene los mismos derechos y responsabilidades (García y Torres, 2004: 86).

En ese sentido, la igualdad entre hombres y mujeres “...no significa identidad con los hombres; significa tener las mismas oportunidades, ser reconocidas y tratadas como iguales, pues cada persona vale igual que cualquier otra persona" (García y Torres, 2004: 86), y alcanza su éxito cuando tanto hombres como mujeres acceden a los derechos.

Ferrajoli, al referirse a los principios de igualdad formal y material indica que:

$[\mathrm{P}]$ artiendo del reconocimiento de su virtual inefectividad [igualdad formal] en presencia de los «obstáculos» de orden económico, social y cultural que la limitan «de hecho»-como los que producen en concreto las múltiples discriminaciones de las mujeres en la vida social y que aquel [principio de igualdad material] prescribe que deben ser «removidas» mediante la introducción de las garantías adecuadas (Ferrajoli, 2004: 76).

En conclusión, la igualdad material es producto de la constatación de los límites de la igualdad formal, cuya inefectividad se verificó en el poco acceso a los derechos por parte de varios grupos sociales que, pese a tenerlos reconocidos, resultaban excluidos debido a la abstracción que se hacía de las diferencias vividas por esos grupos, como la diferencia sexual en el caso de las mujeres, que ha impedido a estas realizar sus derechos. 
Como se señaló anteriormente, en el Ecuador, la demanda de las cuotas electorales como medida de acción afirmativa se fundamentó en el principio de igualdad material y el primer reconocimiento jurídico de la misma, lo hizo el Tribunal Constitucional cuando emitió la resolución N. ${ }^{\circ}$ 028-2002-TC, sobre la validez de las cuotas y la alternancia en el año 2000, en que señaló que estas eran necesarias para superar la discriminación histórica vivida por las mujeres, derivada de la diferencia sexual que obstaculiza el acceso al espacio público y provoca la subrepresentación, tornándose indispensables para garantizar la igualdad.

\section{La paridad más allá del número}

La paridad está aparejada al principio de igualdad material. Al tratarse de la representación, plantea su ejercicio de forma igualitaria entre hombres y mujeres. Pero además se sustenta en la equivalencia entre la composición de la sociedad y la representación, entrando en escena el concepto de "representación-reflejo" (Laporta, 2000: 22; en Villanueva, 2008), por el cual, “... si la mitad de la población son mujeres, la composición de los órganos de decisión debería reproducir, en la mayor medida posible, esa realidad" (Villanueva 2008: 2); así entendida la paridad es una declaratoria de igualdad material permanente.

La Declaración de Atenas (1992) señala que las mujeres, al ser la mitad de la población, son la mitad de las inteligencias y las cualificaciones de la humanidad, y que su ausencia no permite tomar plenamente en consideración los intereses y necesidades del conjunto de la población, por lo cual dicha Declaración convoca a alcanzar un equilibrio entre mujeres y hombres en la representación para alcanzar, con ello, una duradera democracia (cfr. Declaración de Atenas, 1992).

Así, la paridad incluye el concepto de representación de las mujeres y su participación es vital, esto es, que se expresen sus intereses y puntos de vista en los espacios de toma de decisiones políticas. 
En la Asamblea Constituyente se expresó que la paridad no solo se refiere al ejercicio de un derecho sino que trae aparejada la obligación de actuar, desde la representación igualitaria que anhela, en favor de la deconstrucción de

...las relaciones de poder jerárquicas [...] ejercidas desde patrones androcéntricos sexistas y machistas [y las que acceden] deben ayudar a la democratización de las relaciones sociales [de tal modo] que nos lleve como sociedad y como Estado a dar un salto cualitativo, para garantizar la ciudadanía plena, enriquecida por las diversidades (Logroño, 2008: 6).

Este fundamento combina participación con representatividad específica, es decir, la paridad no se limita a defender el acceso, sino que se plantea como medio para la transformación del sistema patriarcal a través de la representación de las mujeres.

Por otro lado, a propósito de la paridad, también se puso en cuestión que si bien las mujeres avanzan en el acceso al espacio público, este continúa siendo masculino, sus reglas, códigos, horarios, etc., son excluyentes para las mujeres y, aún más, no se ha abordado las consecuencias de la división sexual del trabajo pues las mujeres, incluso cuando acceden al espacio público promovidas por la paridad, continúan siendo responsables de las obligaciones del ámbito privado por lo que se plantearon cambios en la relación público-privado aparejados a la demanda de la paridad.

En ese sentido, la Constitución (2008) formula medios de conciliación entre las actividades productivas y las reproductivas estableciendo, por ejemplo, la obligación del Estado de promover un régimen laboral que funcione en armonía con las necesidades del cuidado humano, que facilite servicios, infraestructura y horarios de trabajo adecuados, de manera especial determinando que este deberá proveer de servicios de cuidado infantil, de atención a las personas con discapacidad y otros necesarios para que las personas trabajadoras puedan desempeñar sus 
actividades laborales. En ese mismo propósito, determina la corresponsabilidad y reciprocidad de hombres y mujeres en el trabajo doméstico y en las obligaciones familiares, para lo cual incorpora aspectos como el derecho a licencia por paternidad. Reconoce, además, como labor productiva al trabajo no remunerado de autosustento y al cuidado humano que se realiza en los hogares, considerando a quienes lo hacen como actores y actoras sociales productivas. Adicionalmente regula las relaciones familiares para equilibrarlas entre hombres y mujeres al establecer la corresponsabilidad de padre y madre en el cuidado, crianza, educación, alimentación, desarrollo integral y protección de los derechos de sus hijas e hijos, que debe cumplirse especialmente cuando se encuentren separados de ellos por cualquier motivo, y es el Estado el encargado de vigilar el cumplimiento de los deberes de los progenitores. Por otro lado, busca promover cambios generacionales para lo cual ubica a los jóvenes y las jóvenes como sujetos activos de las labores de autosustento y del cuidado familiar (Art. 67, 68, 324, 325, 329, 331, 332, 333).

En el Consenso de Quito, suscrito por representantes de los Gobiernos de la región en la X Conferencia de la Mujer $(2008)^{3}$, los Estados se comprometieron a:

Adoptar todas las medidas [...] para garantizar la plena participación de las mujeres en cargos públicos y de representación política con el fin de alcanzar la paridad en la institucionalidad estatal [poderes Ejecutivo, Legislativo, Judicial y regímenes especiales y autónomos] y en los ámbitos nacional y local, como objetivo de las democracias latinoamericanas y caribeñas (Consenso de Quito, 2008: N. ${ }^{\circ}$ 1, punto II).

Este es otro instrumento que guía la vigencia de la paridad y que además de la Constitución debe estar presente para evaluar la vigencia efectiva de la paridad en el Ecuador pues, como indica la cita, es necesario "alcanzar la paridad en la institucionalidad estatal”. Esa meta, además de las otras relativas a representatividad, igualdad material, corresponsabi-

3 Celebrada en Quito del 6 al 9 de agosto de 2008, con representantes de los Estados de América Latina y el Caribe. 
lidad entre hombres y mujeres que constituyen el principio de paridad, y a la luz de todos esos componentes, deben ser analizadas y evaluadas.

\section{Las normas paritarias en el Ecuador}

La constitucionalización de la paridad significó, además de elevar al máximo rango jurídico la fórmula paritaria electoral ya aplicada previamente por la Ley de Cuotas (2000), el propagarla a todos los cargos de selección y designación, y el ampliar su influencia a los partidos políticos. La Constitución (2008) en sus artículos 61, numeral 7, y 65, textualmente, dice:

Art. 61.- Las ecuatorianas y ecuatorianos gozan de los siguientes derechos: [...] desempeñar empleos y funciones públicas con base en méritos y capacidades, y en un sistema de selección y designación transparente, incluyente, equitativo, pluralista y democrático, que garantice su participación, con criterios de equidad y paridad de género...

Art. 65.- El Estado promueve la representación paritaria de mujeres y hombres en los cargos de nominación o designación de la función pública, en sus instancias de dirección y decisión, y en los partidos y movimientos políticos. En las candidaturas para las elecciones pluripersonales será obligatoria su participación alternada y secuencial.

Por lo señalado en el Artículo 61, la paridad aplica en general para toda la función pública, no obstante, como norma expresa y mandatoria, se la consagró para la integración del Consejo de Participación Ciudadana y Control Social, el Consejo Nacional Electoral y el Tribunal Contencioso Electoral (Art. 210, 217, 224); y con menor rigor, determinando que se la "promoverá", para el Consejo de la Judicatura, la Corte Nacional de Justicia y la Corte Constitucional (Art. 176, 179, 183, 434), trasladándose en estos últimos casos a la normativa secundaria la facultad de incorporar o no mecanismos paritarios. Las leyes que se han expedido en la etapa postconstituyente recogen literalmente los 
mandatos constitucionales, es decir, reproducen la obligatoriedad de la paridad en relación a los cargos de designación, en aquellas instancias en que está constitucionalmente establecida, pero en los casos en que ésta es opcional no se ha avanzado en diseñar dispositivos paritarios, como tampoco se lo ha hecho para extender la paridad a las instancias no identificadas en la Constitución ni para descenderla a los niveles inferiores de la institucionalidad pues la normativa secundaria hace referencia únicamente a las instancias específicamente señaladas en la Constitución que, obviamente, son las de mayor nivel y solo de algunas instituciones del Estado.

En lo electoral, como se dijo anteriormente, la Constitución (2008) reprodujo la fórmula heredada de la Ley de Cuotas, por lo que solo se refiere a los cargos de elección pluripersonal, esto es la Asamblea Nacional, los concejos regionales y municipales y las juntas parroquiales rurales. De ese modo, excluyó a los puestos que se eligen en listas uninominales. Al respecto, la Constitución dice:

Art. 116.- Para las elecciones pluripersonales, la ley establecerá un sistema electoral conforme a los principios de proporcionalidad [...] paridad y alternabilidad entre mujeres y hombres...

La Constitución también rige para las organizaciones políticas como aparece en el artículo que a continuación se transcribe:

Art. 108.- Los partidos y movimientos políticos [...] garantizarán la [...] conformación paritaria entre mujeres y hombres en sus directivas...

Bajo este nuevo marco constitucional se expidió el Código de la Democracia (2009), que desarrolla la legislación electoral y de partidos políticos en función de las normas constitucionales citadas. Respecto de las elecciones pluripersonales, el Código de la Democracia reprodujo la fórmula establecida en la Ley de Cuotas (2000), esto es que las listas de candidaturas pluripersonales se compongan con el 50\% de hombres y el 50\% de mujeres de forma alternada. Así, la fórmula se limitó a la 
candidatura y no acogió el mandato de paridad relacionado con la representación-reflejo, institucionalizando un método dirigido solamente a la postulación, independientemente del resultado electoral.

Dado que la misma fórmula ha sido aplicada bajo dos regímenes constitucionales y bajo dos distintas normativas legales, se compara los dispositivos sobre igualdad de género de la Ley de Cuotas y el Código de la Democracia (Ver Tabla 1).

Tabla 1.

Comparativo entre Ley de cuotas y Código de la Democracia

\begin{tabular}{|c|c|c|}
\hline & $\begin{array}{c}\text { Ley de Cuotas } \\
\text { (Preconstituyente) }\end{array}$ & $\begin{array}{l}\text { Código de la Democracia } \\
\text { (Postconstituyente) }\end{array}$ \\
\hline Principios & $\begin{array}{l}\text { Equidad e igualdad entre hombres } \\
\text { y mujeres en procesos electorales }\end{array}$ & $\begin{array}{l}\text { Estado constitucional de derechos y } \\
\text { justicia } \\
\text { Interpretación favorable a los derechos } \\
\text { de participación }\end{array}$ \\
\hline Objetivo & Igualdad en la representación & $\begin{array}{l}\text { Igualdad en la representación / } \\
\text { Paridad }\end{array}$ \\
\hline Convocatoria & $\begin{array}{l}\text { Debe constar la fórmula en la } \\
\text { convocatoria a elecciones }\end{array}$ & $\begin{array}{l}\text { Debe constar obligación de cumplir } \\
\text { con principios de equidad paridad, } \\
\text { alternabilidad y secuencia }\end{array}$ \\
\hline Registro de voto & $\begin{array}{l}\text { Voto y escrutinio desagregado por } \\
\text { sexo }\end{array}$ & No contempla \\
\hline $\begin{array}{l}\text { Listas } \\
\text { pluripersonales }\end{array}$ & $\begin{array}{l}\text { Se integran con cuota progresiva } \\
\text { de mujeres, que parte en el } 30 \% \\
\text { y debe crecer hasta alcanzar la } \\
\text { igualdad en la representación. Es- } \\
\text { tablece el principio de alternancia } \\
\text { y secuencia. Alcanzó el } 50 / 50+ \\
\text { alternancia y secuencia }\end{array}$ & $\begin{array}{l}\text { Son paritarias }(50 / 50)+\text { alternancia y } \\
\text { secuencia. Precisa que debe ser hom- } \\
\text { bre-mujer o viceversa. Se eligen en } \\
\text { primarias internas u otros procesos } \\
\text { democráticos }\end{array}$ \\
\hline $\begin{array}{l}\text { Candidaturas } \\
\text { unipersonales }\end{array}$ & No contempla & $\begin{array}{l}\text { Prefectura y viceprefectura se presenta } \\
\text { lista con binomio paritario: hombre- } \\
\text { mujer o mujer-hombre }\end{array}$ \\
\hline Inclusión & Participación étnico-cultural & $\begin{array}{l}\text { Promueve medidas de acción afirma- } \\
\text { tiva para garantizar la participación de } \\
\text { los sectores discriminados }\end{array}$ \\
\hline
\end{tabular}




\begin{tabular}{|c|c|c|}
\hline & $\begin{array}{c}\text { Ley de Cuotas } \\
\text { (Preconstituyente) }\end{array}$ & $\begin{array}{l}\text { Código de la Democracia } \\
\text { (Postconstituyente) }\end{array}$ \\
\hline Exigibilidad & $\begin{array}{l}\text { Organismos electorales deben } \\
\text { negar, de oficio o a petición de } \\
\text { parte, listas que incumplan cuota } \\
\text { y/o alternancia. Sujetos políticos } \\
\text { pueden impugnar }\end{array}$ & $\begin{array}{l}\text { Deber de organismos electorales de } \\
\text { negar de oficio listas que no cumplan } \\
\text { paridad y alternabilidad. Derecho de } \\
\text { impugnación de afiliados/as a partidos } \\
\text { y movimientos políticos }\end{array}$ \\
\hline $\begin{array}{l}\text { Otras } \\
\text { prohibiciones }\end{array}$ & No contempla & $\begin{array}{l}\text { No pueden ser candidatos quienes } \\
\text { adeuden pensiones alimenticias } \\
\text { No se puede realizar propaganda polí- } \\
\text { tica o electoral que discrimine o afecte } \\
\text { la dignidad de las personas }\end{array}$ \\
\hline $\begin{array}{l}\text { Adjudicación } \\
\text { de escaños }\end{array}$ & No contempla & $\begin{array}{l}\text { En caso de producirse empate en el } \\
\text { último escaño entre candidatos de dis- } \\
\text { tinto sexo, se preferirá a la mujer }\end{array}$ \\
\hline $\begin{array}{l}\text { Directivas } \\
\text { partidarias }\end{array}$ & No contempla & $\begin{array}{l}\text { Obligación de paridad. Organismos } \\
\text { electorales, negarán inscripción de di- } \\
\text { rectivas que no cumplan paridad }\end{array}$ \\
\hline $\begin{array}{l}\text { Promoción } \\
\text { electoral }\end{array}$ & No contempla & $\begin{array}{l}\text { Igualdad en la promoción electoral } \\
\text { (difusión de propuestas y candidatu- } \\
\text { ras). Mujeres se benefician en función } \\
\text { de las listas paritarias y alternadas }\end{array}$ \\
\hline Formación & $\begin{array}{l}\text { Capacitación electoral con pers- } \\
\text { pectiva de género }\end{array}$ & $\begin{array}{l}\text { Crea el Instituto de investigación y } \\
\text { análisis político electoral (no especifica } \\
\text { nada sobre formación en género) } \\
\text { Partidos están obligados a hacer for- } \\
\text { mación política con enfoque de dere- } \\
\text { chos humanos, género, igualdad y no } \\
\text { discriminación }\end{array}$ \\
\hline $\begin{array}{l}\text { Conformación } \\
\text { de instancias } \\
\text { electorales }\end{array}$ & No contempla & $\begin{array}{l}\text { Obligación de conformación paritaria } \\
\text { de Consejo Nacional Electoral y Tri- } \\
\text { bunal Contencioso Electoral }\end{array}$ \\
\hline
\end{tabular}

Fuente: Idea Internacional y Comisión Interamericana de Mujeres (2013)

Como puede observarse, en relación a la fórmula paritaria en las listas de candidaturas, la establecida en el Código de la Democracia (2009), es idéntica a la lograda con la Ley de Cuotas (2000). Las diferencias se encuentran en que aquel, agrega listas paritarias para el binomio de prefectura y viceprefectura; prohibición para ser candidatos a quienes 
adeuden pensiones alimenticias; igualdad en la promoción electoral; prohibición a los partidos políticos de realizar propaganda política o electoral discriminatoria; acción afirmativa a favor de las mujeres en caso de producirse empate en el último escaño entre candidatos de distinto sexo al momento de asignar los puestos; obligación de paridad en directivas de partidos políticos con negación de oficio de no cumplirse; y obligación de paridad en las máximas instancias del sistema electoral, a saber, Consejo Nacional Electoral y Tribunal Contencioso Electoral, aspectos que mejoran las condiciones para la participación política de las mujeres y constituyen un indudable avance.

A diferencia del ámbito pluripersonal, los cargos unipersonales carecen de fórmula que obligue a incorporar mujeres. Por elección unipersonal se eligen al presidente o presidenta de la República, que se presenta con un binomio vicepresidencial; a los prefectos o prefectas que dirigen el gobierno provincial; y a los alcaldes o alcaldesas que dirigen los gobiernos cantonales (municipios) y los distritos metropolitanos. El sistema electoral que se aplica es el de mayoría, por el cual, quien alcanza la máxima votación accede al cargo.

La Ley de Cuotas, en su momento, no estableció ningún dispositivo de igualdad de género para este tipo de cargos. El Código de la Democracia (2009) tampoco lo hizo, salvo para el caso de la prefectura y viceprefectura que deben ser presentadas en binomios paritarios, es decir, si la candidatura a la prefectura es masculina, la candidatura de la viceprefectura debe ser femenina y viceversa, lo cual, si bien incentiva a las mujeres, no garantiza la representación reflejo pues es probable que al cargo principal (prefectura) se postulen mayoritariamente varones.

La falta de reglas paritarias en este ámbito puede explicar que durante todo este tiempo, tanto en la candidatura como en la representación de cargos uninominales, se registre un déficit de mujeres en contraste con los avances logrados en el ámbito pluripersonal. 


\section{Análisis de las elecciones 2013}

En las elecciones 2013 se eligieron presidente y vicepresidente de la República, parlamentarios Andinos y representantes a la Asamblea Nacional. Como se señaló anteriormente, el presidente y el vicepresidente se eligen de listas uninominales, bajo un sistema de mayoría en las que no rige ninguna regla paritaria. Se presentaron ocho candidatos a presidente, todos varones, de los cuales seis terciaron junto a un binomio femenino y dos fueron acompañados por un varón.

La competencia para llegar al Parlamento Andino se realiza en listas de candidaturas pluripersonales de cinco postulantes para elegir cinco parlamentarios. Por la fuerza electoral del Movimiento Alianza PAIS, en combinación con la paridad y la alternancia, el Parlamento se compuso con un resultado paritario: dos de las personas electas son mujeres y tres varones.

Si bien el Parlamento Andino obtiene un resultado admitido como paritario, por el reducido número de representantes que se eligen, no será la muestra para realizar este análisis. El análisis se centrará en la elección de los ciento treinta y siete representantes a la Asamblea $\mathrm{Na}$ cional, cuya composición presenta variables en el tamaño de la circunscripción electoral, en la fuerza electoral de las organizaciones políticas y en la conformación de las listas. Tampoco en este estudio se analizará la elección de Presidencia de la República.

\section{Listas y candidaturas a la Asamblea Nacional}

La fórmula paritaria de estructuración de las listas en nuestro sistema electoral se centra en dos elementos: presencia igualitaria de hombres y mujeres, y ubicación alternada de éstos/as a lo largo de la lista. Son estos los principales aspectos que han incidido en la incorporación de mujeres en los espacios de elección popular en los últimos años porque han permitido su nominación y su ubicación en puestos elegibles, 
dando lugar a que más mujeres accedan progresivamente a dichos puestos.

Así, la paridad en la lista pluripersonal está relacionada con la presencia numérica igualitaria de hombres y mujeres dentro de la lista; y la alternancia con la ubicación intercalada de un hombre y una mujer o viceversa a lo largo de la lista, de tal modo que no puedan situarse de forma seguida a dos personas del mismo sexo, elementos que deben observarse tanto para principales como para suplentes.

Para cumplir esa regla, son dos los modelos aplicados en las últimas elecciones: la lista denominada cremallera y aquella que no lo es. Se llama lista cremallera a la que ubica a un hombre, una mujer, un hombre, o una mujer, un hombre, una mujer, en principales, y sus suplentes pertenecen a distinto sexo del principal. En listas impares (para circunscripciones electorales en que se elige un número impar de representantes) diseńadas en cremallera, la paridad se cumple sumando la participación de hombres y mujeres entre principales y suplentes, única manera de equilibrar su participación dado que, precisamente, por ser impar siempre habrá un número mayor de candidaturas de uno de los sexos en cada calidad: principal o suplente.

Tabla 2.

Modelo de lista de cremallera de tres escaños

\begin{tabular}{c|c}
\hline Principal & Suplente \\
\hline Hombre & Mujer \\
\hline Mujer & Hombre \\
\hline Hombre & Mujer \\
\hline
\end{tabular}

Elaboración propia

La lista que no se ajusta al modelo cremallera es aquella en que las suplencias son ocupadas por personas del mismo sexo que las candidaturas principales. En este tipo de lista se cumple de 
manera perfecta la paridad cuando se trata de listas pares (las que se conforman para circunscripciones electorales que eligen un número par de representantes), porque existe igualdad numérica entre hombres y mujeres tanto en principales como en suplentes. El modelo no cremallera en las listas impares no permite la equiparación del número de mujeres y hombres, ni siquiera con la suma global de principales y suplentes, generando mayor disparidad. En el Ecuador no se la usa sino solo para listas pares.

Tabla 3.

Modelo de lista no cremallera de cuatro escańos

\begin{tabular}{c|c}
\hline Principal & Suplente \\
\hline Mujer & Mujer \\
\hline Hombre & Hombre \\
\hline Mujer & Mujer \\
\hline Hombre & Hombre \\
\hline
\end{tabular}

Elaboración propia

La importancia de analizar los dos tipos de listas, además de conocer cómo inciden en el cumplimiento de la paridad, radica en la necesidad de afianzar un modelo que impida cualquier utilización de la fórmula para favorecer a los varones en detrimento de los derechos políticos de las mujeres.

El diseño cremallera ha dado lugar a casos en que, habiendo ganado un puesto una mujer, esta se ve sometida a presiones, violencia política machista o, inclusive, a 'acuerdos' para que con su renuncia pueda acceder al cargo principal su suplente varón. Se conocen varios sucesos de esta naturaleza por testimonios de mujeres que han ocupado distintos cargos de elección popular (entrevista a Margarita Carrasco, 2012) y a través de las redes sociales del uso de similares prácticas inclusive a nivel internacional.

Frente a esos hechos podría definirse que el mejor modelo no es la cremallera sino aquel en que coinciden tanto en principalía como en suplencia candidatos/as del mismo sexo; pero ello a su vez podría 
provocar el efecto adverso de mayor desequilibrio numérico en la participación de mujeres y hombres como candidatos/as, generado por las listas impares en las cuales el porcentaje de varones continúa siendo superior al de mujeres.

Pasando al análisis de los datos, los dos modelos de lista fueron utilizados en las elecciones 2013. Se presentaron doscientas setenta y un cremalleras de un total de trescientas cuarenta y dos listas inscritas a la Asamblea Nacional, lo que equivale al $79 \%$ del total. Listas no cremallera fueron setenta y una, equivalentes al $21 \%$.

\section{Tabla 4.}

Condensado de listas presentadas por circunscripciones pares e impares.

Número y porcentaje de candidatos y candidatas: elecciones 2013 Asamblea Nacional

\begin{tabular}{c|c|c|c|c|c|c|c|c|c|c}
\hline \multirow{2}{*}{$\begin{array}{c}\text { Número } \\
\text { de listas } \\
\text { presenta- } \\
\text { das }\end{array}$} & $\begin{array}{c}\text { Lista } \\
\text { crema- } \\
\text { llera }\end{array}$ & \multirow{2}{*}{$\begin{array}{c}\text { Lista no } \\
\text { crema- } \\
\text { llera }\end{array}$} & \multicolumn{2}{|c|}{ \# Principal } & \multicolumn{2}{|c|}{ \# Suplente } & \multicolumn{2}{|c|}{$\%$ Principal } & \multicolumn{2}{|c}{$\%$ Suplente } \\
\cline { 5 - 11 } & & $\mathrm{H}$ & $\mathrm{M}$ & $\mathrm{H}$ & $\mathrm{M}$ & $\mathrm{H}$ & $\mathrm{M}$ & $\mathrm{H}$ & $\mathrm{M}$ \\
\hline 149 & 149 & 0 & 415 & 328 & 328 & 415 & $56 \%$ & $44 \%$ & $44 \%$ & $56 \%$ \\
\hline 193 & 122 & 71 & 319 & 319 & 319 & 319 & $50 \%$ & $50 \%$ & $50 \%$ & $50 \%$ \\
\hline 342 & 271 & 71 & 734 & 647 & 647 & 734 & $53 \%$ & $47 \%$ & $47 \%$ & $53 \%$ \\
\hline
\end{tabular}

Fuente: Consejo Nacional Electoral e Instituto de la Democracia (2013). Elaboración propia

Como puede observarse en la tabla anterior, el tipo de circunscripción electoral (par o impar) sumado al tipo de lista que se utilice (cremallera o no cremallera) incide en la participación de hombres y mujeres como candidatos y candidatas, pues aún fundiendo las cifras de las listas pares e impares, el porcentaje de varones como principales es mayor al de las mujeres, con el 53\% y 47\%, respectivamente.

Cabe señalar que de las treinta y cinco circunscripciones electorales, quince eligen un número de puestos impar: la nacional con quince escaños; Azuay, El Oro, las cuatro circunscripciones en que se dividió la provincia del Guayas, la circunscripción 2 de Manabí y la circuns- 
cripción 2 de Pichincha, que eligieron cinco escaños; y, las provincias de Bolívar, Cañar, Carchi, circunscripción 4 de Pichincha, Santa Elena y Sucumbíos, con tres escaños. En esas circunscripciones se presentaron un total de ciento cuarenta y nueve listas de candidaturas, de las cuales el $100 \%$ se diseñaron con la fórmula cremallera.

\section{Tabla 5.}

Tipos de listas presentadas en circunscripciones impares. Número y porcentaje de candidatos y candidatas, según lista impar: elecciones 2013 Asamblea Nacional

\begin{tabular}{|c|c|c|c|c|c|c|c|c|c|c|c|c|}
\hline \multirow{2}{*}{ 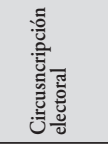 } & \multirow{2}{*}{ 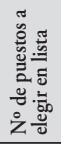 } & \multirow{2}{*}{ 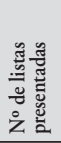 } & \multirow{2}{*}{ 鸪 } & \multirow{2}{*}{ 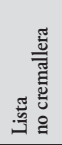 } & \multicolumn{2}{|c|}{ \# Principal } & \multicolumn{2}{|c|}{ \# Suplente } & \multicolumn{2}{|c|}{$\%$ Principal } & \multicolumn{2}{|c|}{$\%$ Suplente } \\
\hline & & & & & $\mathrm{H}$ & M & $\mathrm{H}$ & M & $\mathrm{H}$ & M & $\mathrm{H}$ & M \\
\hline Nacional & 15 & 11 & 11 & 0 & 83 & 82 & 82 & 83 & $50 \%$ & $50 \%$ & $50 \%$ & $50 \%$ \\
\hline Bolivar & 3 & 8 & 8 & 0 & 16 & 8 & 8 & 16 & $67 \%$ & $33 \%$ & $33 \%$ & $67 \%$ \\
\hline Cañar & 3 & 7 & 7 & 0 & 13 & 8 & 8 & 13 & $62 \%$ & $38 \%$ & $38 \%$ & $62 \%$ \\
\hline Carchi & 3 & 10 & 10 & 0 & 19 & 11 & 11 & 19 & $63 \%$ & $37 \%$ & $37 \%$ & $63 \%$ \\
\hline $\begin{array}{l}\text { Resto de } \\
\text { Pichincha }\end{array}$ & 3 & 10 & 10 & 0 & 17 & 13 & 13 & 17 & $57 \%$ & $43 \%$ & $43 \%$ & $57 \%$ \\
\hline Santa Elena & 3 & 13 & 13 & 0 & 25 & 14 & 14 & 25 & $64 \%$ & $36 \%$ & $36 \%$ & $64 \%$ \\
\hline Sucumbíos & 3 & 8 & 8 & 0 & 13 & 11 & 11 & 13 & $54 \%$ & $46 \%$ & $46 \%$ & $54 \%$ \\
\hline Azuay & 5 & 12 & 12 & 0 & 34 & 26 & 26 & 34 & $57 \%$ & $43 \%$ & $43 \%$ & $57 \%$ \\
\hline El Oro & 5 & 8 & 8 & 0 & 21 & 19 & 19 & 21 & $53 \%$ & $48 \%$ & $48 \%$ & $53 \%$ \\
\hline Guayas-1 & 5 & 10 & 10 & 0 & 29 & 21 & 21 & 29 & $58 \%$ & $42 \%$ & $42 \%$ & $58 \%$ \\
\hline Guayas-2 & 5 & 10 & 10 & 0 & 26 & 24 & 24 & 26 & $52 \%$ & $48 \%$ & $48 \%$ & $52 \%$ \\
\hline Guayas-3 & 5 & 10 & 10 & 0 & 28 & 22 & 22 & 28 & $56 \%$ & $44 \%$ & $44 \%$ & $56 \%$ \\
\hline Guayas-4 & 5 & 10 & 10 & 0 & 28 & 22 & 22 & 28 & $56 \%$ & $44 \%$ & $44 \%$ & $56 \%$ \\
\hline Manabí-2 & 5 & 11 & 11 & 0 & 31 & 24 & 24 & 31 & $56 \%$ & $44 \%$ & $44 \%$ & $56 \%$ \\
\hline Pichincha-2 & 5 & 11 & 11 & 0 & 32 & 23 & 23 & 32 & $56 \%$ & $42 \%$ & $42 \%$ & $56 \%$ \\
\hline \multicolumn{2}{|c|}{ TOTALES } & 149 & 149 & 0 & 415 & 328 & 328 & 415 & $56 \%$ & $44 \%$ & $44 \%$ & $56 \%$ \\
\hline
\end{tabular}

Fuente: Consejo Nacional Electoral e Instituto de la Democracia (2013). Elaboración propia 
En referencia a los candidatos y candidatas en las listas impares (Ver Tabla 5), se muestra que para principales se presentaron cuatrocientos quince varones frente a trescientas veintiocho mujeres, lo que equivale al $56 \%$ y $44 \%$ respectivamente, arrojando doce puntos de diferencia entre hombres y mujeres en este tipo de listas.

A modo de hipótesis, podría plantearse que la falta de correspondencia entre el resultado electoral y la candidatura de mujeres, pese a la vigencia de normas paritarias, se debe a que la candidatura masculina continúa siendo mayor en relación a la femenina, derivada de la desigualdad numérica de hombres y mujeres que subsiste en las listas impares. Como se señaló en líneas anteriores, en este tipo de lista la paridad se cumple al sumar el conjunto de candidatos/as entre principales y suplentes ya que estos últimos - precisamente por el efecto cremallera- compensan al sexo con menor número en principales. Por ello los resultados se invierten y del cuadro se verifica que en suplencias hay trescientos veintiocho varones y cuatrocientas quince mujeres, número exactamente inverso al de principales.

Por otro lado, son veinte las circunscripciones en que se elige un número de puestos par: nueve eligen dos escańos, diez eligen cuatro escańos y una elige seis escaños. En este tipo de circunscripción las listas presentadas han acudido a los dos modelos: ciento veintidós bajo el diseño cremallera y setenta y una no cremallera.

Por ser par, en cualquiera de los dos tipos de lista utilizada el número de candidatos/as principales y de suplentes es exactamente igual. Se presentaron trescientos diecinueve hombres candidatos principales y trescientas diecinueve mujeres candidatas, también principales (Ver Tabla 6). Lo propio sucede con las suplencias en que hay trescientos diecinueve hombres candidatos y trescientas diecinueve mujeres candidatas. 
Tabla 6.

Tipos de listas presentadas por circunscripciones pares. Número y porcentaje de candidatos y candidatas, según lista par: elecciones 2013 Asamblea Nacional

\begin{tabular}{|c|c|c|c|c|c|c|c|c|c|c|c|c|}
\hline \multirow{2}{*}{ 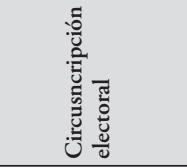 } & \multirow{2}{*}{ 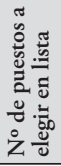 } & \multirow{2}{*}{ 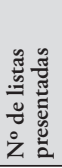 } & \multirow{2}{*}{ 苞 } & \multirow{2}{*}{ 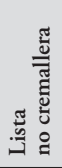 } & \multicolumn{2}{|c|}{ \# Principal } & \multicolumn{2}{|c|}{ \# Suplente } & \multicolumn{2}{|c|}{$\%$ Principal } & \multicolumn{2}{|c|}{$\%$ Suplente } \\
\hline & & & & & $\mathrm{H}$ & M & $\mathrm{H}$ & M & $\mathrm{H}$ & M & $\mathrm{H}$ & M \\
\hline Europa, Asia y Oceanía & 2 & 11 & 7 & 4 & 11 & 11 & 11 & 11 & $50 \%$ & $50 \%$ & $50 \%$ & $50 \%$ \\
\hline EEUU y Canadá & 2 & 10 & 9 & 1 & 10 & 10 & 10 & 10 & $50 \%$ & $50 \%$ & $50 \%$ & $50 \%$ \\
\hline $\begin{array}{c}\text { América Latina, África y } \\
\text { El Caribe }\end{array}$ & 2 & 7 & 5 & 2 & 7 & 7 & 7 & 7 & $50 \%$ & $50 \%$ & $50 \%$ & $50 \%$ \\
\hline Galápagos & 2 & 9 & 6 & 3 & 9 & 9 & 9 & 9 & $50 \%$ & $50 \%$ & $50 \%$ & $50 \%$ \\
\hline Morona Santiago & 2 & 5 & 4 & 1 & 5 & 5 & 5 & 5 & $50 \%$ & $50 \%$ & $50 \%$ & $50 \%$ \\
\hline Napo & 2 & 7 & 6 & 1 & 7 & 7 & 7 & 7 & $50 \%$ & $50 \%$ & $50 \%$ & $50 \%$ \\
\hline Orellana & 2 & 9 & 7 & 2 & 9 & 9 & 9 & 9 & $50 \%$ & $50 \%$ & $50 \%$ & $50 \%$ \\
\hline Pastaza & 2 & 10 & 9 & 1 & 10 & 10 & 10 & 10 & $50 \%$ & $50 \%$ & $50 \%$ & $50 \%$ \\
\hline Zamora Chinchipe & 2 & 8 & 6 & 2 & 8 & 8 & 8 & 8 & $50 \%$ & $50 \%$ & $50 \%$ & $50 \%$ \\
\hline Cotopaxi & 4 & 10 & 5 & 5 & 20 & 20 & 20 & 20 & $50 \%$ & $50 \%$ & $50 \%$ & $50 \%$ \\
\hline Chimborazo & 4 & 11 & 5 & 6 & 22 & 22 & 22 & 22 & $50 \%$ & $50 \%$ & $50 \%$ & $50 \%$ \\
\hline Esmeraldas & 4 & 12 & 4 & 8 & 24 & 24 & 24 & 24 & $50 \%$ & $50 \%$ & $50 \%$ & $50 \%$ \\
\hline Imbabura & 4 & 9 & 8 & 1 & 18 & 18 & 18 & 18 & $50 \%$ & $50 \%$ & $50 \%$ & $50 \%$ \\
\hline Loja & 4 & 10 & 9 & 1 & 20 & 20 & 20 & 20 & $50 \%$ & $50 \%$ & $50 \%$ & $50 \%$ \\
\hline Manabí-1 & 4 & 11 & 4 & 7 & 22 & 22 & 22 & 22 & $50 \%$ & $50 \%$ & $50 \%$ & $50 \%$ \\
\hline Pichincha-1 & 4 & 11 & 6 & 5 & 22 & 22 & 22 & 22 & $50 \%$ & $50 \%$ & $50 \%$ & $50 \%$ \\
\hline Pichincha-3 & 4 & 11 & 4 & 7 & 22 & 22 & 22 & 22 & $50 \%$ & $50 \%$ & $50 \%$ & $50 \%$ \\
\hline $\begin{array}{l}\text { Santo Domingo de los } \\
\text { Tsáchilas }\end{array}$ & 4 & 12 & 6 & 6 & 24 & 24 & 24 & 24 & $50 \%$ & $50 \%$ & $50 \%$ & $50 \%$ \\
\hline Tungurahua & 4 & 11 & 6 & 5 & 22 & 22 & 22 & 22 & $50 \%$ & $50 \%$ & $50 \%$ & $50 \%$ \\
\hline Los Ríos & 6 & 9 & 6 & 3 & 27 & 27 & 27 & 27 & $50 \%$ & $50 \%$ & $50 \%$ & $50 \%$ \\
\hline TOTALES & & 193 & 122 & 71 & 319 & 319 & 319 & 319 & $50 \%$ & $50 \%$ & $50 \%$ & $50 \%$ \\
\hline
\end{tabular}

Fuente: Consejo Nacional Electoral e Instituto de la Democracia (2013). Elaboración propia 


\section{Candidaturas versus resultados electorales}

En las elecciones 2013, resultaron electas cincuenta y tres mujeres de un total de ciento treinta y siete escańos que componen la Asamblea Nacional, equivalente al 39\%. Esta es la cifra femenina más alta de participación en el Parlamento en la historia del Ecuador, confirmando que los mecanismos implementados para la promoción de mujeres en este espacio, a través de las reglas electorales analizadas, han permitido logros importantes en los últimos tres lustros en que se aplican medidas de acción afirmativa, cuotas y paridad.

\section{Gráfico 1.}

Participación de hombres y mujeres en la Asamblea Nacional: elecciones 2013

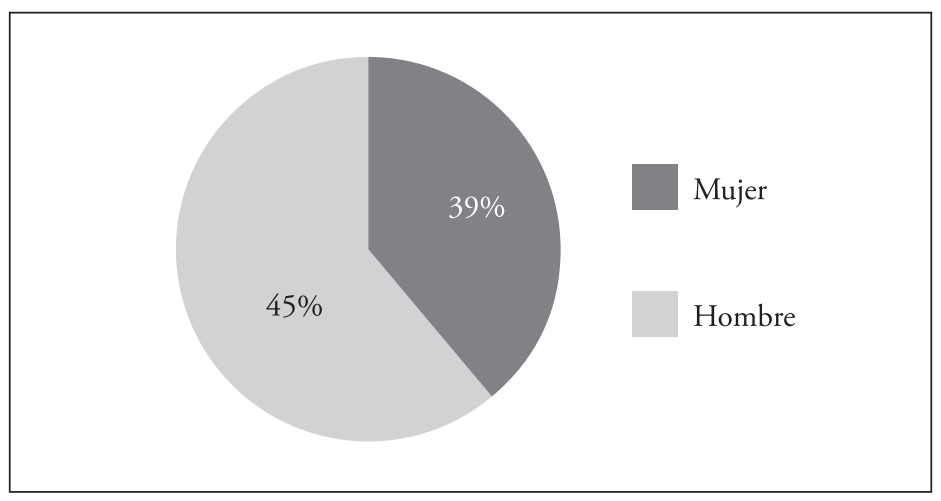

Fuente: Instituto de la Democracia (2013)

No obstante esos avances, la meta de la representación igualitaria entre hombres y mujeres continúa pendiente según el espíritu paritario, esto es igualdad en el resultado electoral. El desbalance entre candidatura y resultado electoral sigue vigente (Ver Gráfico 2), las mujeres parten con una candidatura porcentualmente menor en relación a la de los hombres y en el resultado esa diferencia se acentúa. Así las mujeres descienden del 47\% de candidatura a una representación del $39 \%$ en la Asamblea y en el caso 
de los varones, inician la partida con una candidatura del $53 \%$ y en el resultado mejoran su participación logrando un $61 \%$ de la representación.

Gráfico 2.

Comparación de participación de hombres y mujeres como candidatos/as y electos/as en la Asamblea Nacional: elecciones 2013

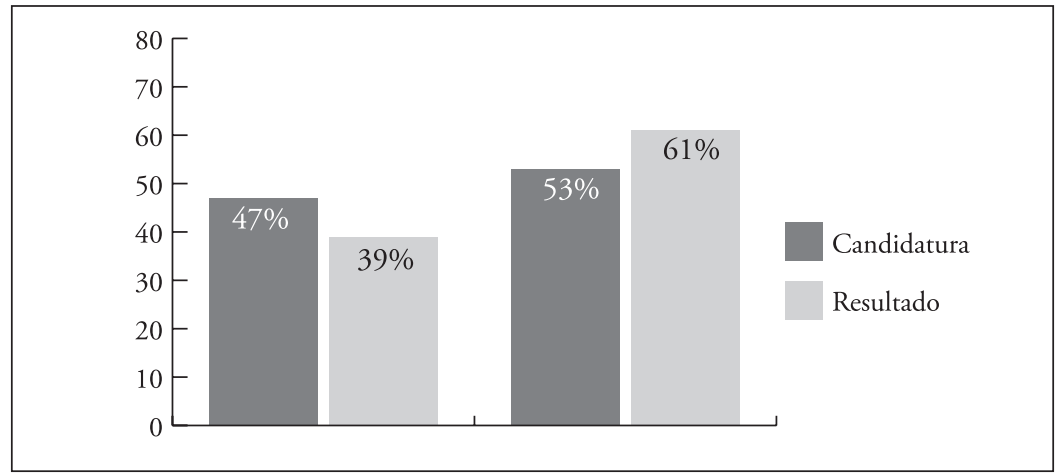

Fuente: Instituto de la Democracia (2013)

Este fenómeno encuentra una de sus causas en la diferencia numérica de hombres y mujeres registrada en las listas de candidaturas, provocada principalmente por la decisión de la organización política al momento de definir su encabezamiento.

Por el modelo de lista paritario vigente en Ecuador, el encabezamiento de la lista determina el peso que cualquiera de los sexos puede tener dentro de ella, especialmente en listas impares. A modo de ejemplo, si una lista impar de tres puestos es encabezada por un varón en principales, se compondrá por dos hombres y una mujer por efecto del mandato de posición (alternancia), y porcentualmente hablando habrá una ventaja para los varones porque alcanzarían el 67\% frente a un 33\% de mujeres. Si la lista es encabezada por una mujer, en el mismo ejemplo, la presencia de mujeres sería mayor al de varones con el 67\% y 33\%, respectivamente.

La obligación legal sobre la paridad en materia electoral, como ha quedado explicado, llega a definir la igualdad numérica entre hombres y 
mujeres y el mandato de posición o alternancia dentro de las listas de candidaturas, pero no regula el encabezamiento, lo que otorga a las organizaciones políticas toda la capacidad de decidir sobre esto. El encabezamiento de la lista es importante no solo porque marca el peso de cualquiera de los sexos en las candidaturas sino, sobre todo, porque la ubicación dentro de la lista genera mayores o menores posibilidades de ser electo/a más allá de las definiciones de nuestro sistema electoral, en relación a la forma de votación que habilita a los electores/as a escoger candidatos de entre listas sin importar el orden en que se encuentren ubicados.

De los datos de las elecciones 2013 en las listas de candidaturas a asambleístas se verifica la predominancia masculina. De trescientas cuarenta y dos listas presentadas para la Asamblea Nacional, doscientas ochenta y una estuvieron encabezadas por varones (Ver Gráfico 3), lo que equivale al $82 \%$, y sesenta y una por mujeres, equivalente al $18 \%$.

\section{Gráfico 3.}

Encabezamiento de listas de candidaturas desagregado por sexo: elecciones 2013-Asamblea Nacional

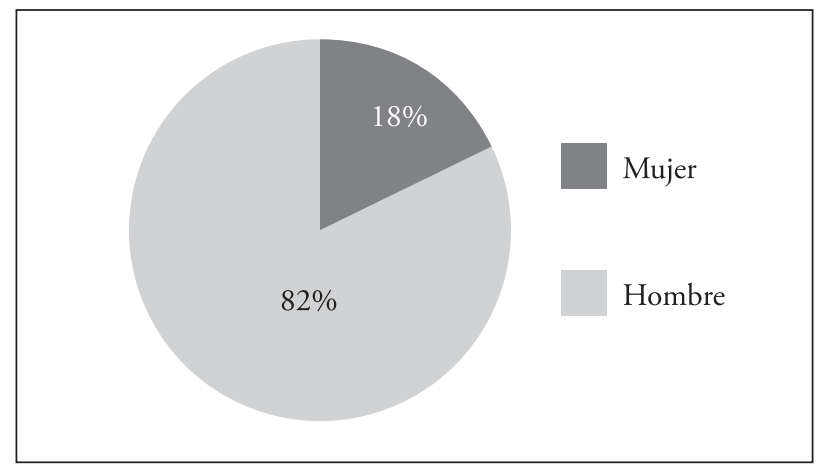

Fuente: Instituto de la Democracia (2013)

En la Tabla 7 se observa que en cuatro provincias: Bolívar, Esmeraldas, Pastaza y Tungurahua, ninguna de las listas presentadas postuló a una mujer como primera candidata, y en treinta y un de los treinta y cinco distritos electorales el liderazgo de los hombres supera el 70\% de las listas. 
Tabla 7.

Encabezamiento de listas de candidaturas desagregado por circunscripción electoral y sexo: Elecciones 2013-Asamblea Nacional

\begin{tabular}{|c|c|c|c|c|c|c|}
\hline $\mathrm{N}^{\circ}$ & Circunscripción electoral & N. ${ }^{\circ} \mathrm{H}$ & N.o M & Total & $\% \mathrm{H}$ & $\% \mathrm{M}$ \\
\hline 1 & Nacional & 6 & 5 & 11 & $55 \%$ & $45 \%$ \\
\hline 2 & Azuay & 10 & 2 & 12 & $83 \%$ & $17 \%$ \\
\hline 3 & Bolívar & 8 & 0 & 8 & $100 \%$ & $0 \%$ \\
\hline 4 & Cańar & 6 & 1 & 7 & $86 \%$ & $14 \%$ \\
\hline 5 & Carchi & 9 & 1 & 10 & $90 \%$ & $10 \%$ \\
\hline 6 & Chimborazo & 10 & 1 & 11 & $91 \%$ & $9 \%$ \\
\hline 7 & Cotopaxi & 9 & 1 & 10 & $90 \%$ & $10 \%$ \\
\hline 8 & El Oro & 5 & 3 & 8 & $63 \%$ & $37 \%$ \\
\hline 9 & Esmeraldas & 12 & 0 & 12 & $100 \%$ & $0 \%$ \\
\hline 10 & Galápagos & 7 & 2 & 9 & $78 \%$ & $22 \%$ \\
\hline 11 & Guayas-1 & 9 & 1 & 10 & $90 \%$ & $10 \%$ \\
\hline 12 & Guayas-2 & 6 & 4 & 10 & $60 \%$ & $40 \%$ \\
\hline 13 & Guayas-3 & 8 & 2 & 10 & $80 \%$ & $20 \%$ \\
\hline 14 & Guayas-4 & 9 & 1 & 10 & $90 \%$ & $10 \%$ \\
\hline 15 & Imbabura & 8 & 1 & 9 & $89 \%$ & $11 \%$ \\
\hline 16 & Loja & 7 & 3 & 10 & $70 \%$ & $30 \%$ \\
\hline 17 & Los Ríos & 7 & 2 & 9 & $78 \%$ & $22 \%$ \\
\hline 18 & Manabí-1 & 9 & 2 & 11 & $82 \%$ & $18 \%$ \\
\hline 19 & Manabí-2 & 9 & 2 & 11 & $82 \%$ & $18 \%$ \\
\hline 20 & Morona Santiago & 4 & 1 & 5 & $80 \%$ & $20 \%$ \\
\hline 22 & Napo & 5 & 2 & 7 & $71 \%$ & $29 \%$ \\
\hline 23 & Orellana & 8 & 1 & 9 & $89 \%$ & $11 \%$ \\
\hline 24 & Pastaza & 10 & 0 & 10 & $100 \%$ & $0 \%$ \\
\hline 25 & Pichincha-1 & 8 & 3 & 11 & $73 \%$ & $27 \%$ \\
\hline 26 & Pichincha-2 & 10 & 1 & 11 & $91 \%$ & $9 \%$ \\
\hline 27 & Pichincha-3 & 9 & 2 & 11 & $82 \%$ & $18 \%$ \\
\hline 28 & Resto de Pichincha & 7 & 3 & 10 & $70 \%$ & $30 \%$ \\
\hline 29 & Santa Elena & 12 & 1 & 13 & $92 \%$ & $8 \%$ \\
\hline 30 & Santo Domingo de los Tsáchilas & 10 & 2 & 12 & $83 \%$ & $17 \%$ \\
\hline 31 & Sucumbíos & 5 & 3 & 8 & $63 \%$ & $37 \%$ \\
\hline 32 & Tungurahua & 11 & 0 & 11 & $100 \%$ & $0 \%$ \\
\hline 33 & Zamora Chinchipe & 7 & 1 & 8 & $88 \%$ & $12 \%$ \\
\hline 33 & EEUU y Canadá & 8 & 2 & 10 & $80 \%$ & $20 \%$ \\
\hline 34 & América Latina, África y El Caribe & 5 & 2 & 7 & $71 \%$ & $29 \%$ \\
\hline 35 & Europa, Ásia y Oceanía & 8 & 3 & 11 & $73 \%$ & $27 \%$ \\
\hline Totales & & 281 & 61 & 342 & $82 \%$ & $18 \%$ \\
\hline
\end{tabular}

Fuente: Instituto de la Democracia (2013) 
La excepción que confirma la regla en este proceso electoral la constituyen las listas nacionales. De las once organizaciones políticas con papeletas electorales, cinco estuvieron encabezadas por mujeres, lo que equivale al $45 \%$, cifra que se sitúa dentro de los rangos paritarios y que revela una ruptura en las relaciones de género en la política. Los análisis de género han demostrado que en la medida que los cargos concentran mayor poder y poseen mayor representación, la presencia de las mujeres disminuye y la de los varones se vuelve hegemónica. Las listas nacionales poseen su propia importancia porque la representación que aspiran sus postulantes se extiende a todo el territorio y a toda la población ecuatoriana, lo que exige liderazgos con mayor posicionamiento y proyección política que los liderazgos locales o regionales, además de enfrentar otros obstáculos de género no superados hasta hace pocos ańos en el proceso de selección de candidaturas. Por la relevancia que tienen las listas nacionales es destacable el alto número de mujeres encabezándolas en niveles casi igualitarios con los varones, lo que podría plantearse como un signo de cambio de la política al interior de las organizaciones políticas al constatar que las mujeres están logrando irrumpir en los espacios políticos de mayor poder interno, lo cual, independientemente de las motivaciones, es una variable democratizadora. Los distritos que le siguen a la lista nacional con una buena presencia de mujeres son $\mathrm{El}$ Oro, Guayas circunscripción 2 y Sucumbíos cuyos encabezamientos alcanzan un 38\%, 40\% y 38\%, de mujeres, respectivamente.

$\mathrm{El}$ análisis por partidos muestra que es el Movimiento PAIS el que mayor número de mujeres como cabezas de listas postula con el 41\%, frente al 59\% de encabezamientos masculinos de un total de veintinueve listas presentadas de forma independiente. Le siguen, bastante atrás, el Movimiento Popular Democrático (MPD) ${ }^{4}$ y el Partido Renovador Institucional Acción Nacional (PRIAN), con el 33\% y 31\% de mujeres en primer puesto dentro de las listas de candidaturas, respectivamente.

4 El MPD de manera independiente, presenta tres listas de candidaturas en las provincias de Chimborazo, Cotopaxi e Imbabura. Las demás las presenta dentro de la Alianza Plurinacional de las Izquierdas, con Pachakutik y otros movimientos políticos. 
Tabla 8.

Encabezamiento de listas de candidaturas desagregado por organización política y por sexo: Elecciones 2013-Asamblea Nacional

\begin{tabular}{c|c|c|c}
\hline Partido & Encabeza hombre & Encabeza mujer & Total \\
\hline PAIS & 17 & 12 & 29 \\
\hline MPD & 2 & 1 & 3 \\
\hline PRIAN & 24 & 11 & 35 \\
\hline Alianzas & 13 & 4 & 17 \\
\hline MUPP-MPD & 24 & 7 & 31 \\
\hline Ruptura & 16 & 4 & 20 \\
\hline PSC & 16 & 3 & 19 \\
\hline Avanza & 27 & 5 & 32 \\
\hline CREO & 22 & 4 & 26 \\
\hline PS-FA & 23 & 4 & 27 \\
\hline PSP & 31 & 4 & 35 \\
\hline Mov. locales & 18 & 1 & 19 \\
\hline Suma & 21 & 1 & 22 \\
\hline PRE & 25 & 0 & 25 \\
\hline MUPP & 2 & 0 & 2 \\
\hline Promedio & 281 & 61 & 342 \\
\hline
\end{tabular}

Fuente: Instituto de la Democracia (2013)

Los datos que se proporcionan (Ver Tabla 8 y Gráfico 4) no permiten concluir que la mayor o menor incorporación de mujeres como cabezas de lista dependa de la ideología partidista porque tanto organizaciones políticas de izquierda (Movimiento PAIS y MPD) como de derecha (PRIAN) aparecen entre aquellas que incentivan a las mujeres para liderarlas; del mismo modo, organizaciones políticas pertenecientes a esas dos antagónicas tendencias aparecen en los lugares con menor número de mujeres encabezando listas, tales como SUMA, que de veintidós papeletas presentadas solamente una tiene encabezamiento femenino, 
o el Partido Socialista que de veintisiete listas, solamente cuatro están lideradas por mujeres.

\section{Gráfico 4.}

\section{Encabezamiento de listas desagregado por partido y por sexo}

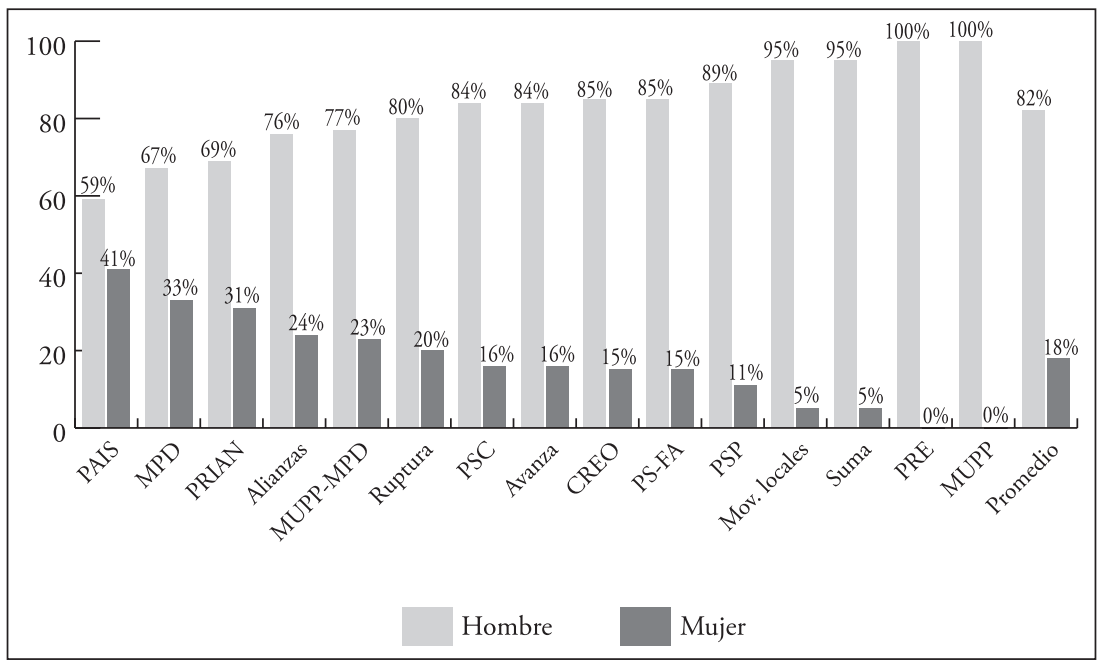

Fuente: Instituto de la Democracia (2013)

La incorporación de mujeres en las listas unipersonales o los encabezamientos de las listas pluripersonales depende de factores distintos a la obligación legal e institucional que gozan la paridad y la alternancia. Están relacionados con la dinámica interna de las organizaciones políticas; es determinante la voluntad de las dirigencias partidarias independientemente de las motivaciones que pudieran tener: captar el electorado femenino puede ser una de esas motivaciones; seguir una corriente de inclusión para no quedarse rezagado en un contexto en que es bien vista la inclusión de mujeres; la movilización interna de las militantes que presionan para que se las considere en la competencia electoral; la existencia de liderazgos fuertes con capacidad política que por su trayectoria y capital político propio están en condiciones 
de negociar dentro del partido; o, inclusive, porque las mujeres, por ser nuevas en política, pueden ser consideradas más dóciles y fáciles de introducir en las lógicas verticales y patriarcales que subyacen en los partidos políticos.

Las elecciones primarias son una buena medida para extraer de la cúpula partidista la potestad de definir quién encabeza una lista porque, aunque desde una perspectiva 'neutra', el encabezamiento se definiría por quien obtenga la mayor votación independientemente de que se trate de un hombre o una mujer; lo que prevalecería sería la aceptación que posean los precandidatos y precandidatas en el universo de votantes preseleccionadores.

El Código de la Democracia (2009) contempla las elecciones primarias como una de las opciones para la selección de candidaturas. Estas fueron usadas de modo excepcional en las elecciones de 2009, pero la generalidad de las organizaciones partidarias prefieren la otra opción que otorga la misma ley, esto es, la selección de candidaturas a través de procesos democráticos internos que pueden ser las asambleas en que se nominan a las y los candidatos.

\section{Acceso según el puesto en la lista de candidaturas}

Los líderes políticos durante el tiempo que se negaron sistemáticamente a aplicar la alternancia regulada en la entonces Ley de Cuotas (2000), sostenían que la ubicación dentro de la lista era irrelevante porque los y las votantes pueden escoger por las y los candidatos de su preferencia entre listas, en virtud del modelo de lista abierta que rige en el Ecuador.

En cada elección se demostró que la ubicación era importante porque menores posibilidades de ser electo/a posee el candidato/a mientras más alejado/a esté del encabezamiento.

Esa realidad no ha variado, los datos indican que el $50,4 \%$, esto es más de la mitad de asambleístas electos y electas, ocuparon el primer puesto en la lista de su candidatura, es decir, encabezaron la lista. Le 
sigue a este grupo, el 19,7\% de asambleístas que estuvieron ubicados en el segundo puesto de la lista y un tercer grupo lo conforman el 16,1\% de asambleístas que ocuparon el tercer lugar en sus listas.

\section{Tabla 9.}

Electos/as según el puesto que ocuparon en la lista

\begin{tabular}{c|c|c}
\hline Puesto en la lista & Número de electos/as & Porcentaje de electos/as \\
\hline Primer puesto & 69 & $50,4 \%$ \\
\hline Segundo puesto & 27 & $19,7 \%$ \\
\hline Tercer puesto & 22 & $16,1 \%$ \\
\hline Cuarto puesto & 10 & $7,3 \%$ \\
\hline Quinto puesto & 6 & $4,4 \%$ \\
\hline Sexto puesto & 1 & $0,7 \%$ \\
\hline Séptimo puesto & 1 & $0,7 \%$ \\
\hline Octavo puesto & 1 & $0,7 \%$ \\
\hline
\end{tabular}

Fuente: Instituto de la Democracia (2013)

Desagregado por sexo los datos de la Tabla anterior, aparece que de sesenta y nueve electos/as que ocuparon el primer puesto en la lista de candidaturas, cuarenta y nueve son varones y veinte mujeres, lo que significa que de los ciento treinta y siete cupos para asambleístas el 36\% de electos fueron varones que encabezaron su lista y el 15\% del total de asambleístas, fueron mujeres cabeza de lista. 
Gráfico 5 .

Electos/as según el puesto que ocuparon en la lista, desagregado por sexo

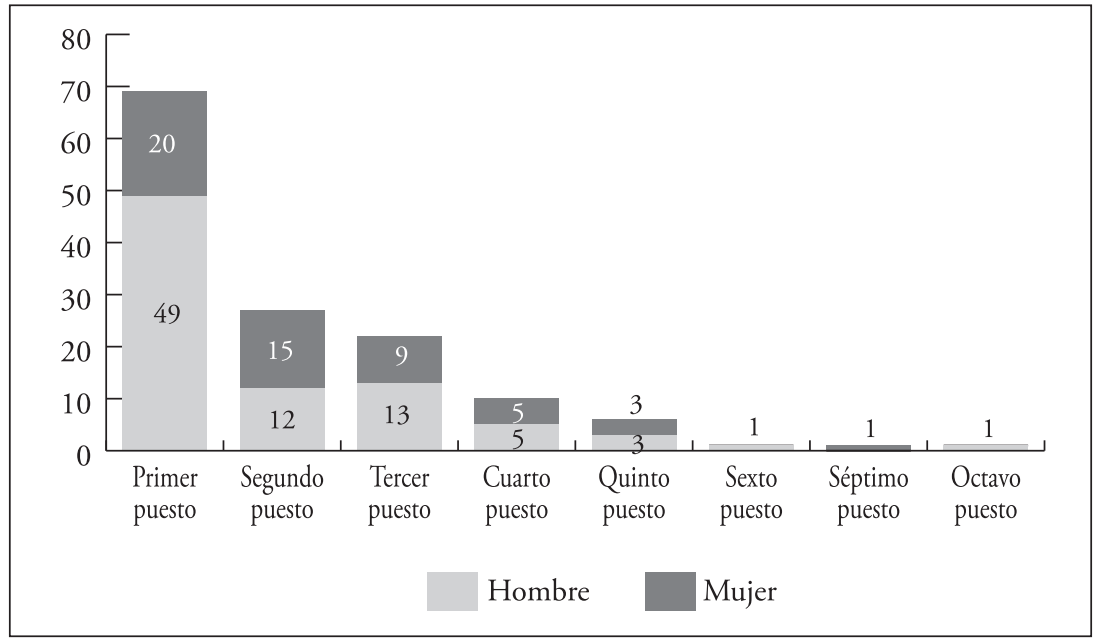

Fuente: Instituto de la Democracia (2013)

De la Tabla 9 y del Gráfico 5 se desprende que el 86\% de los/as electos estuvieron en los tres primeros lugares de la lista. Ese dato es determinante porque guarda relación con la forma de estructurar las listas, su encabezamiento mayoritariamente masculino, además de la fuerza electoral alcanzada por el Movimiento PAIS.

Solo PAIS aporta con asambleístas ubicados/as en los lugares tercero, cuarto, quinto y sexto dentro de las listas de candidaturas, lo que se debe a su fuerza electoral y al método de divisores continuos ( $\left.D^{\prime} H o n d t\right)$ -en circunscripciones provinciales y distritos de Guayas, Pichincha y Manabí- que es considerado mayormente concentrador de la representación. En cuyo caso, las mujeres ingresan por estar ubicadas alternadamente con los varones. Sin duda, es esta organización política la que más aporta con mujeres en la Asamblea Nacional.

Los otros partidos cuyos representantes ingresan como minorías, casi en su totalidad, aportan con varones porque generalmente alcanzan un solo escaño y este, en la mayoría de casos, es ocupado por un varón. 
De los treinta y tres escaños que alcanzan a la Asamblea Nacional los partidos y movimientos diferentes a PAIS, veintisiete son varones y apenas seis son mujeres. Una vez más se confirma la regla de que el encabezamiento es uno de los elementos determinantes para la conformación paritaria o no -en el resultado- de la Asamblea Nacional.

Finalmente, los factores del contexto electoral, en particular la presencia de una fuerza mayoritaria frente a la dispersión de una diversidad de partidos minoritarios, hacen que pese a la forma de votación que faculta elegir candidatos de entre listas, no incida en el resultado electoral dado que la movilidad de los candidatos -que sí existe- no modifica sustancialmente el resultado. El mismo número de mujeres habrían resultado electas con lista cerrada que con lista abierta.

\section{A modo de conclusión}

Ceñidos al análisis de la paridad aplicada en cargos plurinominales de elección popular, se constata que las mujeres han incrementado su participación, no obstante, la representación paritaria en el resultado continúa pendiente.

Las limitaciones de la fórmula paritaria diseñada para lo electoral y que se circunscribe únicamente a la lista de candidaturas pluripersonales, con un mandato de posición que no controla el encabezamiento, inciden directamente para que la deseada paridad en el resultado no se la consiga aún. Dicho de otra manera, la falta de instrumentos paritarios en los otros elementos del sistema electoral, como el tamańo de las circunscripciones electorales y el método de asignación de escaños, son determinantes para que la paridad en el resultado siga pendiente.

Respecto de las elecciones unipersonales no existe regla paritaria que garantice la representación y en la candidatura es restringida a prefecturas y viceprefecturas. Por ello, este ámbito tiene mayor deuda en relación al horizonte paritario en el resultado. La reforma al sistema electoral y reformas al interior de las organizaciones políticas, no solo normativas sino actitudinales, podrían ser una solución a este inconveniente. 
Es necesario estudiar a profundidad los otros factores que inciden en las elecciones y que podrían tener consecuencias en la desigualdad de género como el financiamiento de las campañas, la discriminación y violencia política sexista, entre otros.

Los elementos paritarios que superan la parte numérica para dar luz al nuevo orden de relaciones igualitarias entre hombres y mujeres, referido en la conceptualización de la paridad en este documento, implica la representatividad también paritaria de las mujeres que acceden a los puestos de decisión, lo cual es necesario evaluar mucho más cuando se escucha con mayor frecuencia el descontento ciudadano a esa representación, pues se aduce que lejos de generar un nuevo orden, reproducen el mismo con fuertes signos patriarcales, por lo que la paridad es percibida como meramente numérica y no ha tenido efecto positivo en uno de sus objetivos primarios.

\section{Bibliografía}

Declaración de los Derechos del Hombre y del Ciudadano (1789). Francia. Entrevista a Margarita Carranco (2012), ex Presidenta de la Asociación de Mujeres Municipalistas del Ecuador, AMUME. Quito.

García, Soledad e Isabel Torres (2004). Los derechos humanos de las mujeres: fortaleciendo su promoción y protección internacional. San José: Instituto Interamericano de Derechos Humanos y Centro por la Justicia y el Derecho Internacional.

Goyes, Solanda (2010). "El origen jurídico de las desigualdades en la representación electoral de hombres y mujeres en el Ecuador: una propuesta para la igualdad real". Tesis Doctoral de la Universidad Central del Ecuador, Facultad de Jurisprudencia, Ciencias Políticas y Sociales. Quito.

Ferrajoli, Luigi (2004). Derechos y garantías. La ley del más débil. Editorial Trotta. 
Idea Internacional y Comisión Interamericana de Mujeres (CIM) de la Organización de Estados Americanos (2013). La apuesta por la paridad: democratizando el sistema político en América Latina. Los casos de Ecuador, Bolivia y Costa Rica. Perú (s/e).

Laporta, Francisco (2000). "El cansancio de la democracia". En Claves de Razón Práctica N. 99: 22. Madrid (s/e).

Logrońo, Julieta (2008). "Derechos políticos: propuestas desde las mujeres”. Ponencia presentada en el Panel Democracia paritaria: propuestas, avances y perspectivas en el proceso constituyente, en el Diálogo Constituyente por los derechos humanos de las mujeres del Ecuador. Montecristi.

Primera Cumbre Europea "Mujeres en el Poder" (1992). Declaración de Atenas.

Sartori, Geovanni (2005). Elementos de teoria politica. Madrid: Alianza Editorial.

Valpuesta, Rosario (2008). Contrato Social entre Mujeres y Hombres. Quito: Mimeo.

Villanueva Rocío (2008). "Democracia paritaria, cuotas y sistemas electorales". Ponencia presentada en el Panel Democracia paritaria: propuestas, avances y perspectivas en el proceso constituyente, en el Diálogo Constituyente por los derechos humanos de las mujeres del Ecuador. Montecristi.

X Conferencia de la Mujer (2008). Consenso de Quito, celebrada del 6 al 9 de agosto de 2008.

Normativa y documentos oficiales

Constitución de la República del Ecuador (2008). Asamblea Constituyente. Ciudad Alfaro.

Ley Orgánica Electoral y de Organizaciones Politicas de la República del Ecuador, Código de la Democracia (2009). Asamblea Nacional. Quito: Suplemento R.O. 578 del 27 abril. 
Ley Orgánica de Elecciones (2000). R.O. 117 del 11 julio. Tribunal Constitucional del Ecuador (2002). Resolución 028-2002TC, del 12 de noviembre de 2002, publicada en el Registro Oficial No. 710. Quito. 